\title{
Synthesis of Clotting Factors by the Isolated Perfused Rat Liver*
}

\author{
John P. Olson $\nmid$ Leon L. Miller, $\ddagger$ and Stanley B. Troup \\ (From the Departments of Biochemistry, Medicine, and Radiation Biology, University of \\ Rochester Medical Center, Rochester, N.Y.)
}

The liver has been proposed as a site of synthesis of blood-clotting factors, in part because of the demonstrated dominant role of the liver in synthesis of all plasma protein fractions except the $\gamma$-globulins $(1,2)$. In addition, observations after hepatectomy $(3,4)$ and hepatic injury $(5,6)$ and in hepatic disease $(7,8)$ have provided a body of evidence consistent with hepatic synthesis of fibrinogen, prothrombin, and Factors V, VII, IX, and $\mathrm{X}$. This evidence, however, has not been considered definitive, mainly because it is based on indirect observations in vivo in humans and in animals suffering from variable, often profound, metabolic abnormalities induced by hepatic dysfunction or extirpation.

This report describes the use of the isolated perfused rat liver in a more direct experimental evaluation of the role of the liver in the production of blood-clotting factors. The use of the isolated perfused liver was encouraged by Lupton's observations of shortened prothrombin time during perfusions of 3 to 4 hours (9), and by Pool and Robinson's studies of changes in clotting factor activity during in vitro incubation of rat liver slices (10). Presented here is not only more detailed direct evidence of hepatic synthesis of prothrombin and Factor VII, but also the first direct evidence for hepatic synthesis of Factors V and X.

* Submitted for publication July 2, 1965; accepted January $13,1966$.

This work was supported by U. S. Public Health Service grant HE-04167-05 (HEM) and under contract with the United States Atomic Energy Commission at the University of Rochester Atomic Energy Project, Rochester, N. Y.

Presented in part at the Sixth Annual Meeting of the American Society of Hematology, Washington, D. C., December 10, 1963, and abstracted in Blood 1963, 22, 828.

$\dagger$ This work was completed during the tenure of a Senior Buswell Fellowship in Medicine.

$\ddagger$ Address requests for reprints to Dr. Leon L. Miller, Dept. of Radiation Biology, the University of Rochester School of Medicine and Dentistry, Rochester, N. Y. 14620.
Inhibition of hepatic synthesis of certain of these clotting factors by puromycin and Coumadin, and reversal of the Coumadin effect by vitamin $\mathrm{K}_{1}$ are also described.

\section{Methods}

The perfusion apparatus used in these studies was modified slightly from that described by Miller, Bly, Watson, and Bale in 1951 (11). Important features include two $100-\times 150$-mesh silk filters and a multibulbed gas exchange chamber with a preliver reservoir with an overflow to permit a constant perfusion pressure of 12 to 15 $\mathrm{cm}$ of blood, and a postliver sampling reservoir.

A mixture of $95 \%$ oxygen and $5 \%$ carbon dioxide was humidified and drawn through the gas exchange chamber by an aquarium pump ${ }^{1}$ that provided negative pressure of 0.5 to $1.0 \mathrm{~cm}$ of water. Liberated carbon dioxide was quantitatively absorbed by passage of the gas through $10 \mathrm{ml}$ of a $2: 1$ mixture by volume of 2-methoxyethanol and monoethanolamine (12). This absorbing fluid was changed every 30 minutes and a sample removed for measurement of ${ }^{14} \mathrm{CO}_{2}$ activity in a Packard Tri-Carb liquid scintillation counter. The temperature within the enclosed perfusion apparatus container was maintained at $38.5 \pm 1^{\circ} \mathrm{C}$. A small bore polyethylene tube, terminating in the gas exchange preliver reservoir, was attached to a motor-driven syringe and permitted continuous infusion of drugs, and so on. In these studies perfusion glassware was not siliconized, and pure latex rubber tubing was used for connections between glass components.

Preparation of perfusion fluid. Blood and liver donors were male Sprague-Dawley rats that weighed 400 to 500 g. The animals were fasted 18 hours and allowed free access to water. Blood donors were bled by cardiac puncture under light ether anesthesia. The blood was immediately defibrinated by agitation for approximately 10 minutes in Erlenmeyer flasks containing glass beads. A pool of 90 to $110 \mathrm{ml}$ of defibrinated blood obtained from 6 to 8 animals was filtered through surgical gauze and centrifuged at $3,000 \mathrm{~g}$ for 25 minutes at $4^{\circ} \mathrm{C}$. The serum was separated from the erythrocytes and adsorbed with calcium phosphate gel to remove Factors VII, IX, and $\mathrm{X}$ and residual prothrombin, as described by Stefanini and Dameshek (13). The adsorbed serum was centrifuged for 30 minutes at $4^{\circ} \mathrm{C}$ and $10,000 \mathrm{~g}$ to remove suspended material. Adsorption with calcium phosphate gel resulted in loss of approximately $70 \%$ and $45 \%$ of serum

${ }^{1}$ Marco Co., Bloomfield, N. J. 
calcium and inorganic phosphate, respectively. Calculated amounts of calcium chloride and dibasic sodium phosphate were added to restore these ions to normal concentrations. The serum then was stored overnight at $4^{\circ} \mathrm{C}$.

The rat erythrocytes were washed three times by resuspending them in equal volumes of Ringer's solution and centrifuging at $3,000 \mathrm{~g}$ and $4^{\circ} \mathrm{C}$ for 25 minutes. The washed, packed erythrocytes were stored overnight at $4^{\circ} \mathrm{C}$.

Perfusion fluid was prepared on the morning of perfusion by suspending the washed erythrocytes in the adsorbed serum. Heparin ${ }^{2}$ was diluted in Ringer's solution and added in sufficient quantity to obtain a concentration of approximately $200 \mu \mathrm{g}$ per $\mathrm{ml}$ of perfusion fluid. Glucose, $250 \mathrm{mg}$ (final concentration about $300 \mathrm{mg}$ per $100 \mathrm{ml})$, and $1 \mathrm{ml}$ of L-leucine- $1-{ }^{14} \mathrm{C}(0.61 \mathrm{mg}, 21.7 \mu \mathrm{c}$ per $\mathrm{ml}$ ) were added at the beginning of the perfusions. The initial perfusion volume was 90 to $110 \mathrm{ml}$ with a hematocrit of $28 \pm 3 \%$. Ringer's solution used as wash or diluent at various steps in the preparation of the perfusion fluid composed approximately $20 \%$ of the final perfusion volume.

In some experiments the washed rat erythrocytes were prepared from citrated rat blood (1 part 3.8\% trisodium citrate to 9 parts rat blood). The washed red cells were suspended in an artificial medium composed of modified Tyrode solution with $3 \%$ bovine serum albumin, ${ }^{3} 160 \mathrm{mg}$ of amino acid mixture 4 without leucine, and glucose, heparin, and L-leucine- $1-{ }^{14} \mathrm{C}$ as above.

In some experiments, vitamin $\mathrm{K}_{1}^{5}$ (2-methyl-3-phytyl1,4-naphthoquinone) or Coumadin ${ }^{6}$ [3-(alpha-acetonyl benzyl)-4-hydroxycoumarin] or both were added to the perfusion fluid. Puromycin 7 was added initially and infused continuously into the perfusion fluid in some experiments in the amounts indicated.

Antibiotics were not added to the perfusion fluid. Glass components of the perfusion apparatus were autoclaved before each experiment. Rubber tubing was soaked in $5 \%$ formaldehyde and rinsed with tap water and distilled water before use. Sterile pipettes were used for serial sampling. Cultures of perfusion fluid at the end of experiments were sterile at times, but more frequently bacteria were present. This variable, however, had no apparent influence on clotting-factor assays.

2 Liquaemin sodium, 5,000 U per ml, Organon, Inc., West Orange, N. J.

3 Armour Pharmaceutical Co., Kankakee, Ill.

${ }^{4}$ L-Aspartic acid, $12.3 \%$; L-threonine, $5.6 \%$; L-serine, $6.0 \%$; L-proline, $3.4 \%$; L-glutamine, $8.6 \%$; L-glycine, $6.3 \%$; L-valine, $5.8 \%$; L-methionine, $1.4 \%$; L-isoleucine, $4.5 \%$; L-phenylalanine, $5.5 \%$; L-histidine, $2.4 \%$; L-tryptophan, $2.4 \%$; L-arginine, $12.6 \%$; L-alanine, $8.2 \%$; and L-lysine, $15.0 \%$.

${ }^{5}$ Aquamephyton, $10 \mathrm{mg}$ per $\mathrm{ml}$, Merck Sharp and Dohme, West Point, Pa.

6 Warfarin sodium, $25 \mathrm{mg}$ per $\mathrm{ml}$, Endo Laboratories, Richmond Hill, N. Y.

${ }^{7}$ Nutritional Biochemicals, Cleveland, Ohio.
After defibrination and adsorption with calcium phosphate gel, perfusion fluid was deficient in fibrinogen, prothrombin, and Factors V, VII, VIII, IX, and X. As noted by others (14), we found that Factor $V$ activity of rat plasma was considerably greater than that of human plasma. After defibrination and adsorption, Factor $\mathrm{V}$ activity approximating 10 to $15 \%$ of that present in pooled rat plasma persisted in rat serum. This finding conflicts with the total loss of Factor $\mathrm{V}$ activity reported incidental to clotting of rat blood (15). We suspect that this discrepancy may be due to strain differences in rats, such as have been described for Factor VII (16). Persistence of Factor V activity in Sprague-Dawley rat serum probably is due to relatively high plasma levels of Factor $\mathrm{V}$ in this strain of rats. This finding is considered analogous to the elevated Factor $\mathrm{V}$ activity of bovine plasma and serum (17).

Preparation of isolated intact rat livers. Liver donors were placed under ether anesthesia and, with clean surgical technique employed, the abdomen was opened and complete hepatectomy performed as described by Miller and associates (11). The surgical procedure required 15 to 20 minutes. The liver was without blood flow for approximately 3 minutes.

In some experiments rat liver donors were pretreated with intraperitoneal injections of Coumadin. A dose of $0.2 \mathrm{mg}$ per $100 \mathrm{~g}$ body weight was administered in two divided doses (total dose of 0.7 to $1.0 \mathrm{mg}$ ) 4 and 2 days before the removal of the liver.

Mechanics of perfusion. By suspending the liver platform over a $50-\mathrm{ml}$ graduated centrifuge tube the initial $10 \mathrm{ml}$ of perfusion fluid that passed through the liver was collected and removed from the perfusion system. In this manner preformed coagulation factors were removed from the system. After this, continuity of the perfusion system was restored. Bile was collected from the common bile duct in a graduated centrifuge tube. The volume of bile produced during each sampling period was recorded as a measure of continuing viability of the liver. Five-ml samples of perfusion fluid were removed periodically with a sterile pipette from the sampling reservoir. Samples generally were taken at 5 minutes and $30 \mathrm{~min}$ utes, and then at hourly intervals until perfusion was terminated, usually after 7 hours. Samples of perfusion fluid were transferred immediately to glass tubes containing $0.55 \mathrm{ml}$ of $3.8 \%$ sodium citrate. Citrated perfusion fluid was refrigerated at $4^{\circ} \mathrm{C}$ and centrifuged within 2 hours at $500 \mathrm{~g}$ for 10 minutes. Citrated, heparin-containing supernatant, hereafter referred to as perfusion plasma, was reserved in an ice bath for clotting-factor assays.

Clotting-factor assays. Specific clotting-factor assays were done on serial samples by the following methods: a) The specific prothrombin assay was done as described by Alexander (18). b) The Factor $\mathrm{V}$ assay was done as described by Stefanini (19). c) The Factor VII assay was done as described by Biggs and MacFarlane (20).8

\footnotetext{
8 Human plasma deficient in Factor VII was kindly provided by Dr. Oscar Ratnoff.
} 
d) The assays for Factors VIII and IX were done as described by Breckenridge and Ratnoff (21). e) The Factor $\mathrm{X}$ assay was done as described by Denson (22) except that Gliddex-P,9 suspended in isotonic saline, was used instead of ovolecithin. Stypven Russell's viper venom ${ }^{10}$ and Factor $\mathrm{X}$-deficient substrate plasma ${ }^{11}$ were used. Two $\mathrm{mg}$ per $100 \mathrm{ml}$ Gliddex-P in a $1: 150,000$ dilution of Stypven in barbital buffer (22) proved satisfactory.

The thromboplastin reagent was Bacto-thromboplastin.12 Protamine sulfate (U.S.P.), $50 \mathrm{mg}$ per $\mathrm{ml}^{13}$ was used for heparin neutralization. Dilutions of perfusion plasma and protamine were made in barbital-buffered isotonic saline $(\mathrm{pH} 7.35$ to 7.45$)(18,21)$, hereafter referred to as buffered saline.

Because of the presence of 200 to $300 \mu \mathrm{g}$ of heparin in each milliliter of perfusion plasma, it was necessary to neutralize with protamine before proceeding with specific clotting-factor assays. Pilot studies revealed that heparin added to citrated plasma could be neutralized by protamine with achievement of clotting-factor assay values identical to those of the same citrated plasma without added heparin and protamine. These studies confirmed earlier observations that protamine in excess is a mild anticoagulant (23) but showed also that protamine excesses of up to $50 \mu \mathrm{g}$ per $\mathrm{ml}$ (equivalent to an excess of $1.25 \mu \mathrm{g}$ per $\mathrm{ml}$ in the final assay system) did not change clotting-factor assay values significantly. Although it has been reported that heparin irreversibly inactivates Factor V (24), incubation of citrated rat plasma containing heparin $(200 \mu \mathrm{g}$ per $\mathrm{ml})$ for 5 hours at $37^{\circ} \mathrm{C}$ did not result in irreversible loss of Factor $\mathrm{V}$ activity in this study.

Protamine neutralization of heparin in citrated perfusion plasma was performed as follows. For each experiment, several concentrations $(300,250,200,150$, and 100 $\mu \mathrm{g}$ per $\mathrm{ml}$ ) of protamine sulfate in barbital-buffered isotonic saline were prepared and placed in the ice bath. Since specific prothrombin and Factor V, VII, and X assays each required a $1: 10$ dilution of test plasma, it was convenient to add protamine at the step of plasma dilution. The dilution then was $0.8 \mathrm{ml}$ barbitalbuffered isotonic saline: $0.1 \mathrm{ml}$ protamine solution (one of the five concentrations above) : $0.1 \mathrm{ml}$ perfusion plasma.

In general, protamine concentrations of 150 to $250 \mu \mathrm{g}$ per $\mathrm{ml}$ were found to be optimal; that is, the shortest clotting time in each of the specific factor assays resulted when protamine concentrations in this range were used. Initially, the optimal protamine concentration was determined in each specific factor assay on each sample of perfusion plasma. The Factor $\mathrm{X}$ assay was found to be most sensitive to excesses of protamine and, after the first few experiments, this assay system was used exclusively to determine the optimal protamine concentration.

${ }^{9}$ Chemurgy Division, Glidden Co., Chicago, Ill.

10 Burroughs Wellcome and Co., New York, N. Y.

11 Diagnostic Reagents, Ltd., Thame, Oxon, England.

12 Difco Laboratories, Detroit, Mich.

13 Eli Lilly and Co., Indianapolis, Ind.
Initially, also, the optimal protamine concentration was determined for each serial sample of perfusion plasma in each experiment. After several perfusions it became evident that the optimal protamine concentration for heparin neutralization fell some $100 \mu \mathrm{g}$ per $\mathrm{ml}$ late in the course of perfusion. The optimal protamine concentration then was established for the 5-minute sample and determined again after 2 or 3 hours, 5 hours, and 7 hours of perfusion. In puromycin experiments, during which a loss of clotting factor activity was observed (see Results), more frequent determinations of optimal protamine concentration were made.

For reference purposes, samples of pooled, citrated rat plasma were frozen and stored at $-20^{\circ} \mathrm{C}$. At intervals during this study they were thawed and serial dilutions made in buffered saline. Specific factor assays described above were performed on serial dilutions by using the same technique as in the perfusion experiments. Dilution curves for each specific clotting factor were constructed. This procedure served as a check on the stability of the reagents. It also made possible an estimation of the activity of individual clotting factors in the samples of perfusion plasma as an approximate per cent of specific factor activity present in pooled normal rat plasma.

\section{Results}

Results of specific clotting-factor assays on serial samples of rat liver perfusates are expressed below as assay clotting times in seconds rather than as per cent of normal rat plasma activity. The maximal activity each factor reached during respective perfusions was estimated by reference to dilution curves of pooled, citrated rat plasma described above and is recorded in the legend of each Figure.

Results for prothrombin and Factors $\mathrm{V}$ and $\mathrm{X}$ are recorded under four sets of experimental conditions. A total of 40 separate perfusions were performed during this investigation. ${ }^{14}$ Results of

14 The results of all perfusions have not been included here for several reasons. Most importantly, the results of clotting assays from different experiments cannot be numerically pooled. The legends for all Figures cite the numbers and results of experiments not illustrated. A number of early perfusions failed to run smoothly for more than 3 to 5 hours, even after the perfusion apparatus was autoclaved. The ultimate use of calcium phosphate gel instead of aluminum hydroxide and especially the replacement of calcium and phosphate in the adsorbed perfusion medium (see Methods) were important in prolonging the duration of experiments to 7 hours. The results of several other early experiments were rendered incomplete because of technical difficulties in some of the clotting-factor assays. It is to be emphasized that each liver perfusion serves as its own control. 


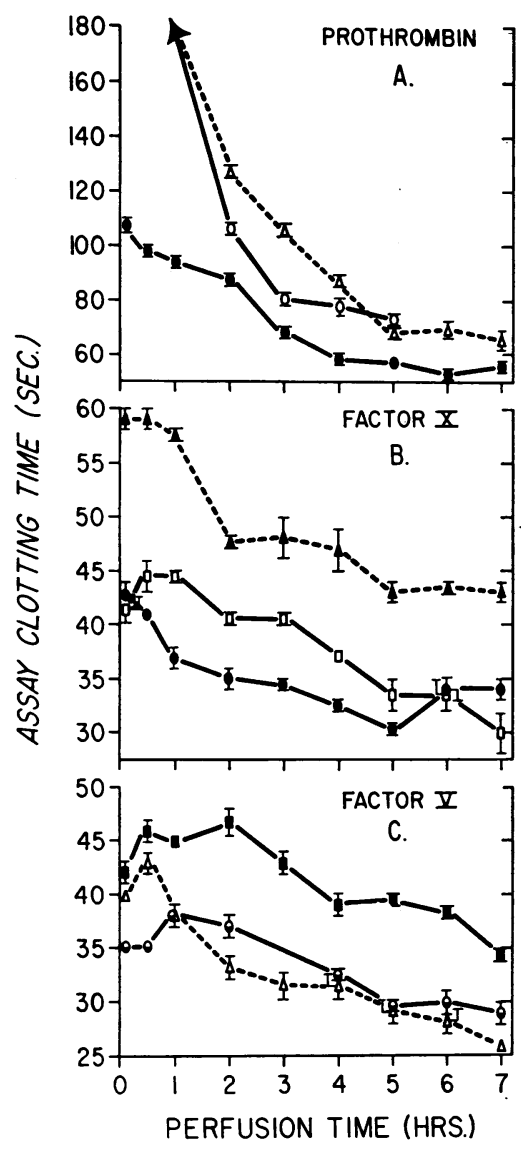

Fig. 1. Prothrombin, Factor $\mathrm{X}$, and Factor V asSAYS OF PERFUSATES OF NORMAL RAT LIVERS. Isolated rat livers were perfused with diluted adsorbed rat serum containing resuspended rat erythrocytes (solid lines) or artificial plasma containing resuspended rat erythrocytes (dashed lines). The arrowhead at the start of the two curves indicates that the assay clotting times measured at 0,30 , and 60 minutes were all greater than 180 seconds. Approximate increases in clotting activity of the perfusates, expressed as per cent of normal pooled rat plasma are, for prothrombin, from less than $2 \%$ to 10 to $15 \%$, for Factor X, from less than $2 \%$ to 20 to $40 \%$, and for Factor V, from 10 to $15 \%$ to 30 to $50 \%$ (solid lines) and from $0 \%$ to 15 to $20 \%$ (dashed lines). In this and all subsequent Figures the results of duplicate clotting-factor assays on each plasma specimen are indicated by the extremes of the bars through each point on the curve, which is the mean of the duplicate observations. In this and all subsequent Figures, results taken from any one perfusion experiment are assigned the same symbol, i.e., open circles, closed triangles, closed circles, and so forth. All specific factor assays were not done in each experiment; this explains the occasional lack of correspondence of symbols in sections $\mathrm{A}, \mathrm{B}$, and $\mathrm{C}$ of Figures 1,2 , and 3 .

In addition to the results of typical experiments shown in section A above, specific prothrombin time measurements were made on samples taken at the same times two or three typical perfusion experiments are shown for each factor under each of the four sets of experimental conditions.

Control experiments (Figure 1). Normal (i.e., untreated) rat livers were perfused. In Figure 1 and subsequent experiments, solid lines illustrate results obtained in typical experiments in which the perfusion fluid was composed of adsorbed rat serum and washed rat erythrocytes. In Figure 1 dashed lines illustrate results obtained in typical experiments in which artificial plasma (see Methods) was substituted for adsorbed rat serum.

A) Prothrombin. Figure 1, section A, illustrates the progressive shortening of prothrombin assay clotting times on serial samples of normal rat liver perfusates in three experiments. The change in assay clotting time is approximately equivalent to an activity increase from less than $2 \%$ at the start of perfusion to 10 to $15 \%$, expressed as a per cent of normal pooled rat plasma activity.

$B$ ) Factor $X$. Figure 1, section B, illustrates the progressive shortening of Factor $\mathrm{X}$ assay clotting times of normal rat liver perfusates in three experiments. The change in per cent activity is from $2 \%$ or less at the beginning to 20 to $40 \%$ of pooled normal rat plasma Factor X activity.

$C)$ Factor $V$. As noted above (see Methods), residual Factor $\mathrm{V}$ activity (approximating 10 to $15 \%$ of that in normal pooled rat plasma) was present in the adsorbed rat serum at the onset of perfusion. This fact is reflected in the relatively modest decrease in Factor $\mathrm{V}$ assay clotting times

from 15 perfusions of normal livers with rat red cells and defibrinated absorbed rat plasma and from four perfusions with red cells in artificial plasma. The results from all 19 perfusions were grossly similar to those illustrated, with substantial, grossly significant, persistent decrease in observed clotting times.

In addition to the typical curves in section $B$ above, specific clotting time assays for Factor $\mathrm{X}$ were similarly carried out on samples from two perfusions with red cells in defibrinated absorbed heparinized plasma. The results from all 15 perfusions were grossly similar to those illustrated above with grossly significant, persistent decreases in clotting times.

In addition to the typical curves in section $\mathrm{C}$ above, results of specific Factor $\mathrm{V}$ assays were obtained from 11 perfusions (seven with red cells in artificial plasma and four with red cells in defibrinated absorbed heparinized plasma). In all perfusions, significant persistent decreases in Factor V assay clotting times were observed. 


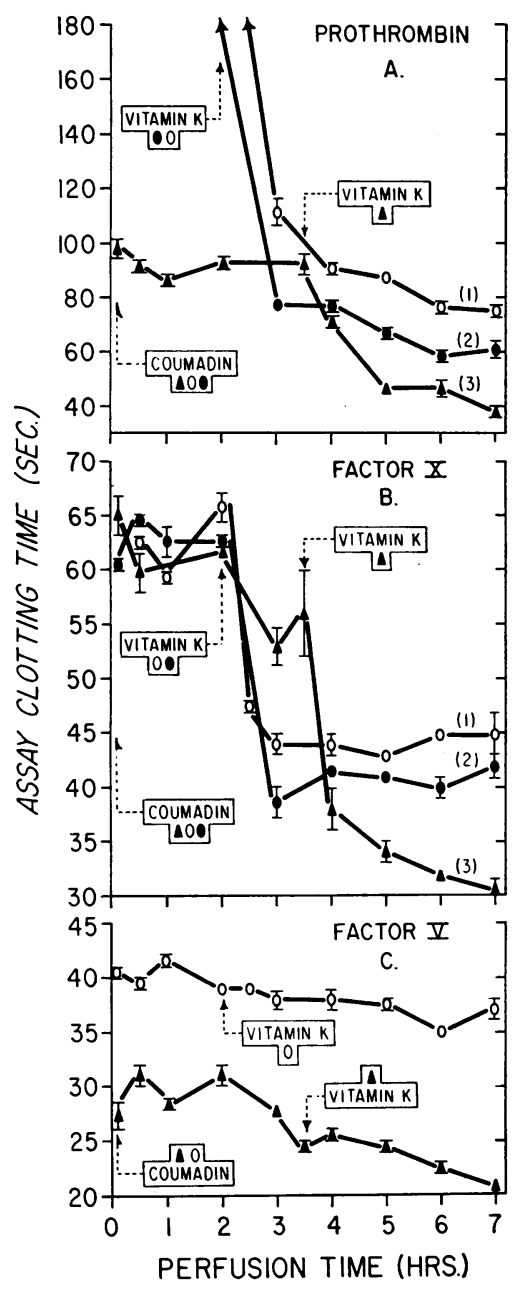

Fig. 2. Prothrombin, Factor $\mathrm{X}$, and Factor V asSAYS OF PERFUSATES OF COUMADIN-TREATED RAT LIVERS BEFORE AND AFTER ADDITION OF VITAMIN $K_{1}$. Coumadin was administered to rat liver donors 4 and 2 days before hepatectomy (total dose, $0.2 \mathrm{mg}$ per $100 \mathrm{~g}$ body weight). Coumadin $(0.5 \mathrm{mg})$ also was added to perfusates at zero time. Vitamin $\mathrm{K}_{\mathbf{1}}(2 \mathrm{mg})$ was added to perfusates at 2 or $3 \frac{1}{2}$ hours. Arrowheads at start of two upper curves in section $\mathrm{A}$ indicate that clotting times of prothrombin assays of samples taken at $0, \frac{1}{2}, 1$, and 2 hours were all greater than 180 seconds. The final activity reached by each of the three factors after addition of vitamin $K_{1}$ closely approximates that reached at the end of normal liver perfusions (Figure 1).

In addition to the results of the specific prothrombin, Factor X, and Factor V assays illustrated above, samples from two more perfusions of livers from Coumadintreated rats showed grossly similar significant responses to addition of vitamin $\mathrm{K}$ with decreases in prothrombin and Factor $\mathrm{X}$ assay clotting times. As in section $\mathrm{C}$ above, no effect of Coumadin or vitamin $\mathrm{K}$ on Factor $\mathrm{V}$ assay clotting time was observed. observed in Figure 1, section C. The dashed lines, from a typical experiment using artificial plasma, show greater over-all shortening in clotting time, as the initial level of Factor $\mathrm{V}$ was lower. The points of the curve marked by closed boxes correspond to serial samples, which were diluted 1:50 before the Factor V assay was perfused, whereas points on the other two curves were obtained by using 1:10 dilutions of the perfusion plasma.

Coumadin and vitamin $K_{1}$ experiments (Figure $2)$. Liver donors were pretreated with intraperitoneal injections of Coumadin, as detailed in Methods. The perfusate included Coumadin $(0.5 \mathrm{mg})$, which was added at zero time to the sampling reservoir. Vitamin $K_{1}(2 \mathrm{mg})$ was added to the perfusate at 2 or 3.5 hours, as indicated in Figure 2.

A) Prothrombin. Figure 2, section A, illustrates failure of prothrombin assay clotting times to shorten during perfusion of Coumadin-treated isolated rat livers. The addition of vitamin $K_{1}$ at 2 hours (curves 1 and 2 ) or at 3.5 hours (curve 3 ) is followed, within 30 to 60 minutes, by shortening of the prothrombin assay clotting time. Final levels approximate closely those levels reached in control experiments. The shorter clotting times during the first $3 \frac{1}{2}$ hours of perfusion illustrated in curve 3 are surmised to be related to the presence of residual prothrombin activity in that particular "prothrombin-free" substrate reagent used in the assay.

B) Factor $X$. The perfusates of Coumadintreated livers develop little or no Factor $\mathrm{X}$ activity (Figure 2, section B). Addition of vitamin $\mathrm{K}_{1}$ after 2 hours (curves 1 and 2 ) or 3.5 hours of perfusion (curve 3 ) is followed within 30 to 60 minutes by shortening of Factor $\mathrm{X}$ assay clotting times in serial samples of the perfusates. Final values approximate those of control experiments.

$C$ ) Factor $V$. Coumadin treatment of perfused livers and subsequent addition of vitamin $\mathrm{K}_{1}$ after 2 or 3.5 hours had no significant effect on Factor $\mathrm{V}$ levels in the perfusates. Factor $\mathrm{V}$ assay curves in Figure 2, section $\mathrm{C}$, approximate those of the normal control experiments.

Puromycin experiments (Figure 3). The antibiotic puromycin, a known general inhibitor of protein synthesis, was added to the perfusion fluid at zero time, and an equal amount was infused continuously during perfusion. A total combined dose 


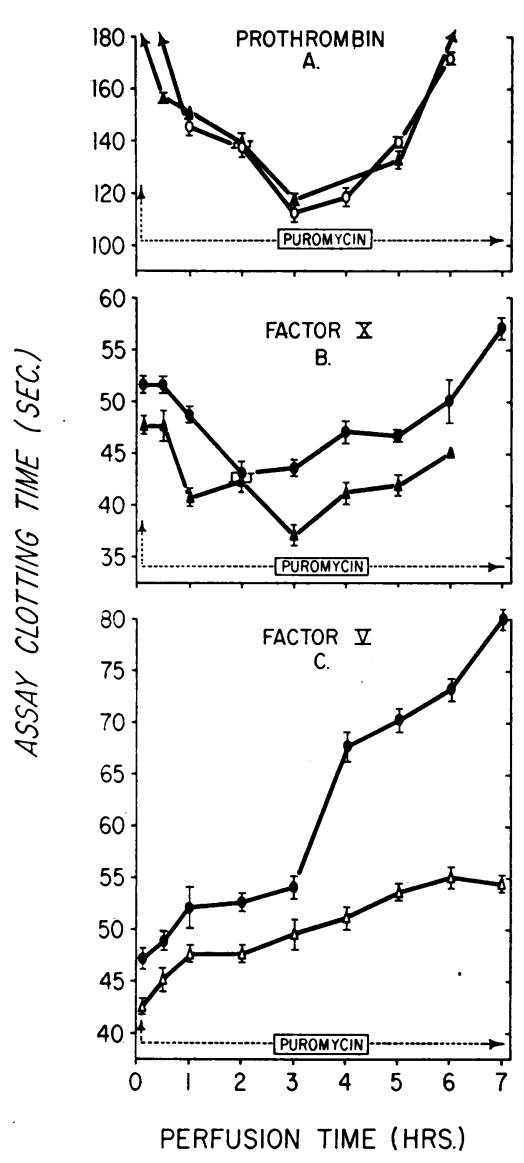

Fig. 3. Prothrombin, Factor X, and Factor V asSAYS OF PERFUSATES OF PUROMYCIN-TREATED RAT LIVERS. Puromycin was added to the perfusion fluid at zero time and an equal amount infused continuously (total dose, 30 $\mathrm{mg}$ ). Arrowheads at start of curve in A indicate that clotting times of assays of samples taken at 0 and $30 \mathrm{~min}-$ utes were greater than 180 seconds. Expressed as per cent of normal, pooled rat plasma activity, prothrombin activity rose to $5 \%$ from initial levels of $2 \%$ and then fell to less than $2 \%$. Factor $\mathrm{X}$ activity rose to 10 to $15 \%$ from initial levels of $5 \%$ and then fell to less than $5 \%$. Factor $\mathrm{V}$ activity, on the other hand, decreased steadily from initial values of $10 \%$ to final levels of 1 to $3 \%$. The early transient increase in prothrombin and Factor $\mathrm{X}$ activity may be due to completion of partially formed proteins and is discussed in the text.

In addition to the specific prothrombin assays of two perfusions in section A above, the effect of puromycin introduced at zero time was studied in four more perfusions of otherwise normal livers. In all four perfusions, the observed specific prothrombin times decreased minimally in two during the first 3 or 4 hours or not at all. In the last 2 hours, prothrombin assay clotting times were increased to values not significantly different from those of samples taken at the outset.

The pattern of change in Factor X clotting assays of the of $30 \mathrm{mg}$ of puromycin was chosen because this is sufficient to completely prevent incorporation of L-leucine- $1-{ }^{14} \mathrm{C}$ into fibrinogen by the isolated perfused rat liver (2). The perfusion conditions were identical to the control experiments in other respects.

A) Prothrombin. Some prothrombin activity appears initially in perfusates of isolated rat livers perfused with puromycin (Figure 3, section A). This activity is less than that observed in control or Coumadin-vitamin $\mathrm{K}$ experiments, and the activity disappears during the last 3 to 4 hours of perfusion.

$B$ ) Factor $X$. The puromycin-treated liver initially adds Factor $\mathrm{X}$ activity to the perfusion fluid, as is shown in Figure 3, section B; however, as was true of prothrombin, less activity appears than in Coumadin-vitamin $\mathrm{K}$ experiments. During the last 3 to 4 hours of perfusion, Factor $\mathrm{X}$ activity also decreases progressively.

$C$ ) Factor $V$. Figure 3, section $\mathrm{C}$, shows that the Factor $\mathrm{V}$ activity initially present gradually disappears from perfusates of puromycin-treated livers. This is in sharp contrast to the modest shortening of Factor V assay clotting times observed during control or Coumadin-vitamin $\mathrm{K}_{1}$ perfusion experiments.

Coumadin, puromycin, and vitamin $K_{1}$ experiments (Figure 4). In this set of experiments, the effect of puromycin on the response of Coumadintreated livers to vitamin $\mathrm{K}_{1}$ was studied. Liver donors were pretreated with Coumadin as described previously. Coumadin $(0.5 \mathrm{mg})$ was added to perfusates at zero time. Puromycin (15 $\mathrm{mg}$ ) was added to perfusates at zero time and an equal amount ( $15 \mathrm{mg})$ infused continuously. Vitamin $\mathrm{K}_{1}(2 \mathrm{mg})$ was added after 2.5 hours of perfusion.

A) Prothrombin. Despite the perfusion of isolated livers with Coumadin and puromycin, the addition of vitamin $K_{1}$ after 2.5 hours is followed by the appearance of prothrombin activity (Figure 4 , section A). Shortening of the prothrombin assay clotting time is somewhat less than in con-

four additional perfusions was grossly identical with that seen in section $B$, above.

In addition to the results seen in section $C$ above, Factor $\mathrm{V}$ assays were carried out in two puromycin perfusions. Results obtained showed minimal increases in the clotting times over the course of the perfusions. 


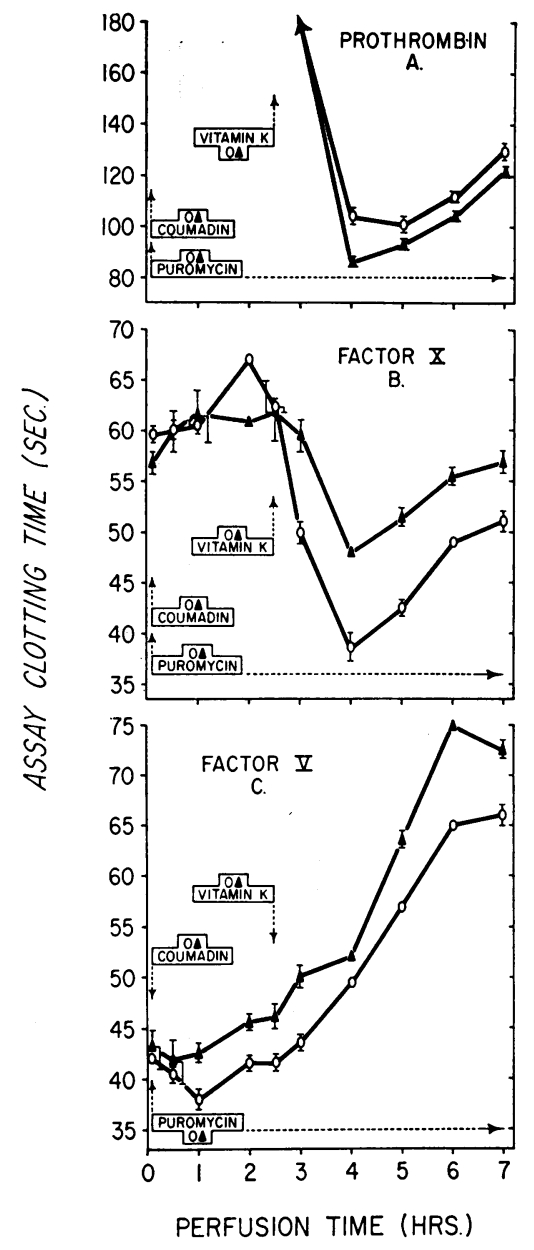

Fig. 4. Prothrombin, Factor $\mathrm{X}$, and Factor V asSAYS OF PERFUSATES OF RAT LIVERS TREATED WITH COUMADIN AND PUROMYCIN BEFORE AND AFTER ADDITION OF VITAMIN $K_{1}$. Coumadin was administered to rat liver donors 4 and 2 days before hepatectomy (total dose, $0.2 \mathrm{mg}$ per $100 \mathrm{~g}$ body weight). Coumadin $(0.5 \mathrm{mg})$ also was added to perfusates at zero time. Puromycin was added to perfusates at zero time and an equal amount infused continuously (total dose, $30 \mathrm{mg}$ ). Vitamin $\mathrm{K}_{1}(2 \mathrm{mg}$ ) was added to perfusates at $2 \frac{1}{2}$ hours. Arrowheads at start of curves in section A indicate that clotting times of assays of samples taken at $0, \frac{1}{2}, 1,2$, and 3 hours were greater than 180 seconds. The changes in prothrombin, Factor $\mathrm{X}$, and Factor $\mathrm{V}$ activity of perfusates, expressed as per cent of normal pooled rat plasma, closely approximate the respective changes observed in the puromycin experiments (Figure 3).

In one additional perfusion of a liver from a Coumadintreated rat, puromycin in the same dosage was added to the perfusion fluid at 2 hours (and infused) followed by vitamin $\mathrm{K}$ at $2 \frac{1}{2}$ hours. The effects on prothrombin, Factor $\mathrm{X}$, and Factor $\mathrm{V}$ assays were grossly similar to those seen in sections $\mathrm{A}, \mathrm{B}$, and $\mathrm{C}$, respectively. trol or Coumadin-vitamin $\mathrm{K}$ experiments. Assay clotting times invariably gradually lengthen during the last 3 hours of perfusion as in puromycin experiments (see Figure 3 ).

$B$ ) Factor $X$. Figure 4, section $B$, illustrates that the addition of vitamin $\mathrm{K}_{1}$ to perfusates of combined Coumadin- and puromycin-treated livers is followed within 30 to 90 minutes by the appearance of Factor $\mathrm{X}$ activity. After this initial response, however, Factor $\mathrm{X}$ assay clotting times gradually lengthen during the last 3 hours of perfusion.

In summary, despite continuous perfusion of Coumadin-treated livers with puromycin, the administration of vitamin $\mathrm{K}_{1}$ is followed by the appearance of measurable prothrombin and Factor $\mathrm{X}$ activity in the perfusates. Subsequently, however, prothrombin and Factor $\mathrm{X}$ activities gradually disappear, as in experiments in which isolated livers are perfused with puromycin alone.

$C$ ) Factor $V$. Figure 4, section $\mathrm{C}$, shows gradual lengthening of Factor $\mathrm{V}$ assay clotting times during perfusions of rat livers with Coumadin and puromycin. The addition of vitamin $K_{1}$ is without effect on Factor $\mathrm{V}$ assay clotting times, in contrast to the prothrombin and Factor $\mathrm{X}$ assays. Curves for Factor $\mathrm{V}$ activity are essentially identical to those obtained when isolated livers are perfused with puromycin alone (see Figure 3 ).

Factor VII (Figure 5). Because of limited quantities of substrate plasma deficient in Factor VII, it was not always possible to do Factor VII assays in duplicate experiments.

Results of Factor VII assays in five experiments are recorded in Figure 5. With one exception, these results are identical to those obtained for prothrombin and Factor $\mathrm{X}$ in the same experiments. The perfusate of a normal (untreated) rat liver develops increasing Factor VII activity (graph A). Factor VII activity does not appear in perfusates of livers pretreated and perfused with Coumadin until 30 minutes after addition of vita$\min K_{1}$ to the perfusion fluid (graphs $B$ and D). In three experiments using puromycin (graphs $\mathrm{C}$ and $\mathrm{D}$ ), no progressive lengthening of Factor VII assay clotting times occurred during the last 3 to 4 hours of perfusion. This is in contrast to the consistent loss of activity observed for prothrombin and Factors $\mathrm{V}$ and $\mathrm{X}$ at these times in these same experiments. In two experiments 
(graph D), puromycin had no apparent effect on the response of Coumadin-treated livers to vita$\min \mathrm{K}_{1}$.

Factors VIII and IX. Efforts to demonstrate Factor VIII or IX activity in perfusates under the various experimental conditions described above were negated by wide and apparently random vari-

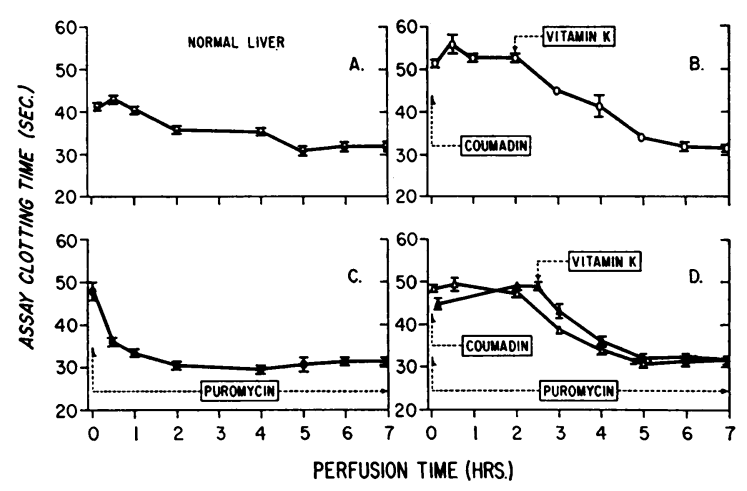

Fig. 5. Factor VII assays of Rat liver perfusates. Results for Factor VII obtained under each of the four experimental conditions described in Figures 1 to 4 are shown in sections $A, B, C$, and $D$, respectively. Per cent activity is not expressed, as no dilution curves for Factor VII activity in pooled citrated rat plasma were prepared.

The availability of only a small amount of human Factor VII deficient plasma restricted specific Factor VII assays to the five experiments depicted above. However, to the extent that assay for Factors (II + VII $+\mathrm{X}$ ) is a valid measure of Factor VII activity, mention of the following is pertinent.

Measurements of Factors (II + VII $+\mathrm{X}$ ) activity were made on samples from perfusions of 11 normal livers (three with red cells in artificial plasma, eight with red cells in defibrinated absorbed heparinized plasma); results were quantitatively and qualitatively analogous to those shown in graph $\mathrm{A}$, above.

Measurements of Factors (II + VII + X) were made on samples from perfusions of livers from Coumadintreated rats with vitamin $\mathrm{K}$ added at 0 time in two, and at 2 hours in two. The clotting times decreased sharply after vitamin $\mathrm{K}$ to give curves grossly analogous to those in graph $\mathrm{B}$, above.

In two of the four normal liver perfusions with puromycin, the clotting times for Factors (II + VII $+\mathrm{X}$ ) were all greater than 3 minutes. In the other two puromycin perfusions, the clotting times decreased to $75 \mathrm{sec}-$ onds and 125 seconds, respectively, at 3 hours, and then increased to 125 seconds and greater than 3 minutes, respectively, at 7 hours.

In the three perfusions of livers from Coumadin-treated rats in which puromycin was added, followed by vitamin $\mathrm{K}$ (see Figure 4) the pattern of clotting times from assay of Factors (II + VII + X) was identical with that shown in section $\mathrm{A}$ of Figure 4.
TABLE I

Failure of puromycin, vitamin $K_{1}$, and/or Coumadin to affect specific factor assay systems

\begin{tabular}{|c|c|c|c|}
\hline \multirow{2}{*}{$\begin{array}{l}\text { Material added to } \\
\text { aliquots of diluted } \\
\text { citrated rat plasma }\end{array}$} & \multicolumn{3}{|c|}{$\begin{array}{l}\text { Assays for specific factors } \\
\text { (clotting time) }\end{array}$} \\
\hline & Prothrombin & Factor V & Factor $\mathrm{X}$ \\
\hline & & seconds & \\
\hline Buffered saline & $58 / 56$ & $28 / 29$ & $32 / 32$ \\
\hline $\begin{array}{l}\text { Puromycin, } \\
\qquad(0.35 \mathrm{mg} / \mathrm{ml})^{*}\end{array}$ & $59 / 59$ & $27 / 28$ & $34 / 33$ \\
\hline $\begin{array}{l}\text { Vitamin } \mathrm{K}_{1} \\
\quad(0.03 \mathrm{mg} / \mathrm{ml})^{*}\end{array}$ & $58 / 57$ & $28 / 28$ & $32 / 34$ \\
\hline $\begin{array}{l}\text { Coumadin, } \\
(0.03 \mathrm{mg} / \mathrm{ml})^{*}\end{array}$ & $56 / 58$ & $29 / 29$ & $33 / 32$ \\
\hline $\begin{array}{l}\text { Puromycin, } \\
\text { vitamin } \mathrm{K}_{1} \text {, and } \\
\text { Coumadin } \dagger\end{array}$ & $57 / 58$ & $27 / 29$ & $32 / 33$ \\
\hline
\end{tabular}

* Concentrations of the respective agents in aliquots of the diluted citrated rat plasma.

t Concentrations of each of the three agents is the same as in the previous aliquots of diluted citrated rat plasma.

ations in Factor VIII and IX assay clotting times on serial samples. It often was difficult to obtain satisfactory agreement between duplicate or triplicate determinations on the same sample.

Assay control studies. $A$ ) The possibility of a direct effect of puromycin, Coumadin, or vitamin $\mathrm{K}_{1}$ on assays for prothrombin and Factor $\mathrm{V}$ or $\mathrm{X}$ was explored (Table I). Citrated rat plasma was diluted in buffered saline and five aliquots prepared. Buffered saline alone was added to one. Solutions of puromycin, Coumadin, or vitamin $\mathrm{K}_{1}$ in buffered saline were added to three. A mixture of these three agents was added to the fifth aliquot. In each case the final concentration of each additive was equal to the estimated maximal concentration of the additive in the perfusion plasma.

TABLE II

The absence cf anticoagulant or clot-accelerating activity in perfusates of rat livers treated with Coumadin, puromycin, and vitamin $K_{1}$

\begin{tabular}{ccc}
\hline \hline $\begin{array}{c}\text { Perfusate sample } \\
\text { added to citrated } \\
\text { rat plasma }\end{array}$ & \multicolumn{2}{c}{$\begin{array}{c}\text { Assays for specific factors } \\
\text { (clotting time) }\end{array}$} \\
\cline { 2 - 3 } & Factor V & Factor $\mathrm{X}$ \\
Sample $1^{*}$ & \multicolumn{2}{c}{ seconds } \\
Sample 2† & $24 / 24$ & $35 / 34$ \\
& $25 / 25$ & $31 / 32$
\end{tabular}

* Sample 1 was obtained before addition of Coumadin, puromycin, and vitamin $K_{1}$ to perfusate.

† Sample 2 was obtained from the residual perfusate at the end of a 7-hour perfusion during which Coumadin, puromycin, and vitamin $K_{1}$ were added. 
The results shown in Table I reveal no consistent inhibition or acceleration of coagulation.

$B$ ) The possibility that anticoagulant or clotaccelerating activity developed during perfusion of the liver with a perfusate containing puromycin, Coumadin, and vitamin $\mathrm{K}_{1}$ also was studied (Table II). Two samples of perfusion plasma were collected from an experiment in which these agents were used. The first (sample 1) was collected before these agents were added. The second ( sample 2) was collected at the end of a 7-hour experiment during which these agents were used. Each of two aliquots of normal citrated rat plasma was diluted $1: 1$ with one of these samples. Both Factor $\mathrm{V}$ and $\mathrm{X}$ assays were then done on the mixtures. The results, shown in Table II, reveal no significant difference in Factor $\mathrm{V}$ assay clotting times. The slight shortening of the Factor $\mathrm{X}$ assay clotting time is surmised to reflect the absence of Factor $\mathrm{X}$ activity in adsorbed rat serum (sample 1) and the presence of some Factor $\mathrm{X}$ activity after 7 hours of perfusion of a Coumadin-treated liver with puromycin, Coumadin, and vitamin $K_{1}$ (sample 2).

Such control studies provide no evidence for significant direct action of Coumadin, puromycin, or vitamin $K_{1}$, singly or in combination, upon the clotting factor assays per se. These control studies also fail to demonstrate development of anticoagulant or clot-accelerating activity during perfusions in which puromycin, Coumadin, and vita$\min \mathrm{K}_{1}$ are used.

\section{Discussion}

Previous efforts to elucidate the site or sites of synthesis of clotting factors have resulted in agreement that the liver is the site of synthesis of fibrinogen, prothrombin, and Factors V, VII, and X (25). Most of the evidence for this view is indirect and rests upon observations in intact animals after hepatic injury or disease or extirpation of the liver. The recent use of liver slice, immunofluorescent, and isolated intact liver perfusion techniques has afforded more direct observations and circumvented some interpretative difficulties of earlier work.

The use of immunofluorescent techniques in the study of hepatic prothrombin localization by Barnhart and Anderson $(26,27)$ has yielded cir- cumstantial but not definitive evidence for hepatic synthesis of prothrombin. Despite efforts to ensure specificity of the antiprothrombin antiserum, the observations have not been accepted without reservation (25). Since intact animals were used in Barnhart's study, it is not possible to exclude a significant contribution by nonhepatic tissues. Finally, despite advances in understanding of protein synthesis at the molecular level, the roles of vitamin $\mathrm{K}_{1}$ and coumarins in elaboration of coagulation factor activity have not been clarified.

The studies of Pool and Robinson (10) reveal that functional prothrombin and Factor VII appear during incubation of isolated metabolically active hepatic cells. These observations are consistent with hepatic synthesis of these two clotting factors. However, the lack of precise knowledge about the action of Coumadin and the other metabolic inhibitors used again complicates interpretation. Furthermore, free tissue thromboplastin in the incubation medium, as suggested by the authors, might result not only in rapid utilization of prothrombin and Factors V and VIII, but also might activate Factor VII and thereby contribute to the apparent increase in Factor VII activity.

The present studies have been designed to obtain direct evidence for hepatic synthesis of clotting factors by isolated perfused intact rat liver in a system that approximates the physiological state. These studies demonstrate that perfusates from the isolated liver develop prothrombin and Factor V, VII, and X activity. This recently has been confirmed by Mattii, Ambrus, Sokal, and Mink (28), although Factors VII and X were not assayed separately in their study. In neither our study nor that of Mattii and his colleagues did the maximal activities of the various factors assayed exceed $40 \%$ of normal levels in rat plasma, and they generally were much less. A possible explanation for this observation exists in the fact that the initial perfusion volume is three to four times the normal rat blood volume. The modest increments in activity detected in both studies raise the possibility that the appearance of specific factor activity in the perfusate is the result of washout of preformed clotting factors previously present in hepatic interstitial fluid, on cell surfaces, or within cells. However, our studies of the effect of supplying vitamin $\mathrm{K}_{1}$ to isolated, perfused, Coumadin-treated livers indicate that active he- 
patic metabolism is responsible. Under these conditions, little or no prothrombin or Factor VII or $\mathrm{X}$ activity appeared in perfusates until 30 to 60 minutes after addition of vitamin $K_{1}$. The ultimate similarity between the levels of these three clotting factors in the normal control and in the Coumadin-vitamin $\mathrm{K}_{1}$ perfusions suggests that normal perfused livers also are actively involved in the addition of these clotting factors to the perfusion fluid.

Our observations suggest hepatic synthesis of prothrombin and Factor VII and X, but they also are compatible with at least two other interpretations. It is possible that Coumadin blocks and vi$\operatorname{tamin} \mathrm{K}$ is necessary for release of these three factors, which are formed elsewhere and merely stored in the liver. The above-cited studies by Barnhart and Anderson and by Pool and Robinson strongly suggest, however, that no significant hepatic storage of prothrombin or Factor VII takes place under the influence of Coumadin. It is conceivable that inactive precursors of prothrombin, Factor VII, and Factor X are synthesized in nonhepatic sites despite the presence of Coumadin and stored in the liver, where vitamin $K_{1}$ is required to produce the physiologically active clotting factors. Neither our observations on the effects of Coumadin and vitamin $K_{1}$, nor the studies of Barnhart or Pool exclude this possibility. Our studies with puromycin discussed below suggest, however, that the role of the liver in clotting-factor synthesis is more than that of a site for storage and conversion of a protein precursor.

The observation that Factor $\mathrm{V}$ activity in the liver perfusates was unaffected by Coumadin or subsequent addition of vitamin $K_{1}$ is consistent with numerous in vivo observations in man and animals. That a difference between Factor $\mathrm{V}$ on one hand and prothrombin, Factor VII, and Factor $\mathrm{X}$ on the other was observed in the Coumadinvitamin $\mathrm{K}$ experiments is partial confirmation that specific factors were measured by respective assays. Results of normal control and Coumadinvitamin $\mathrm{K}_{1}$ perfusions do not exclude the possibility, however, that the small increments of Factor V activity measured represented material synthesized before hepatectomy and washed out of the isolated liver during perfusion.

Studies of perfusates of puromycin-treated livers provide additional information on the role of the liver in synthesis of the clotting factors. When puromycin was present in liver perfusates, prothrombin and Factor $\mathrm{X}$ activity first appeared for 2 to 3 hours, and then these activities progressively disappeared with Factor $\mathrm{V}$ activity. This initial appearance of small amounts of prothrombin and Factor $\mathrm{X}$ activity may represent completion of molecules partially formed before puromycin was added, as well as washout of molecules present in hepatic cells or interstitial fluid. With further synthesis blocked by puromycin, prothrombin, Factor V, and Factor X activities gradually decrease as the factors are catabolized, inactivated, or utilized during mild continuous coagulation, which probably occurs in the perfusion system. These observations could also be explained by the appearance of a circulating anticoagulant, which interfered with assays for Factor V, Factor X, and prothrombin. Alternatively, in the presence of puromycin, a circulating accelerator of coagulation may have appeared and caused utilization of these three factors at a rate exceeding their rate of synthesis by the liver. The control studies performed to test these hypotheses, however, failed to demonstrate either anticoagulant or coagulation-accelerating activity in the perfusion fluid.

The interpretation of the puromycin effect that is most attractive to us is that this agent interferes with hepatic synthetic elaboration of prothrombin, Factor V, and Factor X activity. The present concept of puromycin action strongly suggests that it is hepatic synthesis of these proteins that is blocked. Since 1959, when Yarmolinsky and De la Haba demonstrated that puromycin interfered with incorporation of leucine into liver protein (29), puromycin has been utilized extensively in studies of protein synthesis. The initial suggestion that puromycin interference with protein synthesis was a result of its structural similarity to that portion of "transfer" RNA coupled with amino acid (29), has received support from recent studies which demonstrate that puromycin interferes with completion of polypeptide chains on the ribosome (30).

Observations of effects of puromycin on the response of perfused Coumadin-treated livers to vitamin $K_{1}$ provide evidence for the site of action of Coumadin and vitamin $K_{1}$. Prothrombin, Factor VII, and Factor $\mathrm{X}$ activity appeared after addition of vitamin $\mathrm{K}_{1}$ to the Coumadin-perfused liver, de- 
spite prior perfusion of puromycin for $2 \frac{1}{2}$ to $3 \frac{1}{2}$ hours. It thus seems likely that Coumadin and vitamin $K_{1}$ act later than puromycin during synthesis of these three clotting factors. In this hypothesis, the liver is able to synthesize incomplete, inactive precursors of prothrombin, Factor VII, and Factor $\mathrm{X}$ in the presence of Coumadin. Puromycin interrupts further synthesis of these precursors but not completion of preformed precursors upon addition of vitamin $\mathrm{K}_{1}$. Other evidence suggests that an inactive precursor of prothrombin may be present in plasma in dietary or coumarininduced vitamin $\mathrm{K}$ deficiency (31).

Failure of Factor VII to behave similarly to prothrombin and Factor $\mathrm{X}$ in puromycin experiments has been adequately explained. It may be that: a) Factor VII and its activated form may not be inactivated or catabolized by the liver; $b$ ) elaboration of Factor VII activity is not directly dependent on protein synthesis (32); and $c$ ) since Factor VII apparently is involved only in the extrinsic coagulation system, it requires tissue thromboplastin for activation and utilization. It is possible that the mild continuous coagulation often observed in the perfusion system does not involve tissue thromboplastin.

The above studies provide direct evidence for synthesis of prothrombin and Factors V, VII, and $\mathrm{X}$ by the liver. More refined proof requires demonstration of net synthesis and labeling of purified coagulation proteins, thus far accomplished only for fibrinogen (33). The technique of isolated intact organ perfusion merits further attention as an approach to these studies.

\section{Summary}

The role of the liver in synthesis of coagulation factors has been studied by the technique of isolated, intact rat liver perfusion. Direct evidence for synthesis of prothrombin and Factors V, VII, and $\mathrm{X}$ by the liver has been obtained. Inhibition of synthesis of prothrombin, Factor VII, and Factor $\mathrm{X}$ by Coumadin and reversal of inhibition by vitamin $\mathrm{K}_{1}$ have been demonstrated. The lack of effect of Coumadin and vitamin $\mathrm{K}_{1}$ on Factor $\mathrm{V}$ synthesis has also been demonstrated. Further evidence for hepatic synthesis of prothrombin, Factor V, and Factor X has been obtained by use of puromycin as inhibitor of protein synthesis.
Studies with puromycin in combination with Coumadin and vitamin $K$ suggest that the latter two agents act between ribosomal synthesis and the appearance of active prothrombin, Factor VII, and Factor $\mathrm{X}$.

\section{Acknowledgments}

The authors gratefully acknowledge the technical assistance of Mrs. Elaine Kreiling and Miss Julie Brown during this investigation.

\section{References}

1. Miller, L. L., and W. F. Bale. Synthesis of all plasma protein fractions except gamma globulins by the liver. The use of zone electrophoresis and lysine-e$\mathrm{C}^{14}$ to define the plasma proteins synthesized by the isolated perfused liver. J. exp. Med. 1954, 99, 125.

2. Miller, L. L., H. R. Hanavan, N. Titthasiri, and A. Chowdhury. Dominant role of the liver in biosynthesis of the plasma proteins with special reference to the plasma mucoproteins (seromucoid), ceruloplasmin and fibrinogen. Advances in Chemistry Series, 44, Amino Acids and Serum Proteins, American Chemical Society, 1964, p. 17.

3. Zucker, M. B., M. Siegel, E. E. Cliffton, J. W. Bellville, W. S. Howland, and C. E. Grossi. The effect of hepatic lobectomy on some blood clotting factors and on fibrinolysis. Ann. Surg. 1957, 146, 772.

4. Mann, F. D., E. S. Shonyo, and F. C. Mann. Effect of removal of the liver on blood coagulation. Amer. J. Physiol. 1951, 164, 111.

5. Smith, H. P., E. D. Warner, and K. M. Brinkhous. Prothrombin deficiency and the bleeding tendency in liver injury (chloroform intoxication). J. exp. Med. 1937, 66, 801.

6. Sykes, E. M., Jr., W. H. Seegers, and A. G. Ware. Effect of acute liver damage on Ac-globulin activity of plasma. Proc. Soc. exp. Biol. (N. Y.) 1948, 67, 506.

7. Finkbiner, R. B., J. J. McGovern, R. Goldstein, and J. P. Bunker. Coagulation defects in liver disease and response to transfusion during surgery. Amer. J. Med. 1959, 26, 199.

8. Rapaport, S. I., S. B. Ames, S. Mikkelsen, and J. R. Goodman. Plasma clotting factors in chronic hepatocellular disease. New Engl. J. Med. 1960, 263, 278.

9. Lupton, A. M. The effect of perfusion through the isolated liver on the prothrombin activity of blood from normal and Dicumarol treated rats. J. Pharmacol. exp. Ther. 1947, 89, 306.

10. Pool, J. G., and J. Robinson. In vitro synthesis of coagulation factors by rat liver slices. Amer. J. Physiol. 1959, 196, 423. 
11. Miller, L. L., C. G. Bly, M. L. Watson, and W. F. Bale. The dominant role of the liver in plasma protein synthesis. A direct study of the isolated perfused rat liver with the aid of lysine- $\epsilon-C^{14}$. J. exp. Med. 1951, 94, 431.

12. Jeffay, H., and J. Alvarez. Liquid scintillation counting of carbon-14. Use of ethanolamine-ethylene glycol monomethyl ether-toluene. Analyt. Chem. 1961, 33, 612.

13. Stefanini, M., and W. Dameshek. The Hemorrhagic Disorders, 2nd ed. New York, Grune \& Stratton, 1962, p. 450.

14. Lewis, J. L. Personal communication.

15. Murphy, R. C., and W. H. Seegers. Concentration of prothrombin and Ac-globulin in various species. Amer. J. Physiol. 1948, 154, 134.

16. Grodsky, G. M., M. Kropatkin, and J. G. Pool. Deficient synthesis of Factor VII by liver tissue of fetal and newborn rats. Amer. J. Physiol. 1960, 199, 139.

17. Alexander, B., R. Goldstein, and G. Landwehr. The labile factor of prothrombin conversion: its consumption under normal and pathological conditions affecting blood coagulation. J. clin. Invest. 1951, 30, 252.

18. Tocantins, L. M. The Coagulation of Blood; Methods of Study, 1st ed. New York, Grune \& Stratton, 1955, p. 94.

19. Stefanini, M. New one-stage procedures for the quantitative determination of prothrombin and labile factor. Amer. J. clin. Path. 1950, 20, 233.

20. Biggs, R., and R. G. MacFarlane. Human Blood Coagulation and Its Disorders, 3rd ed. Philadelphia, F. A. Davis, 1962, p. 389.

21. Breckenridge, R. T., and O. D. Ratnoff. Studies on the nature of the circulating anticoagulant directed against antihemophilic factor: with notes on an assay for antihemophilic factor. Blood 1962, 20, 137.

22. Denson, K. W. The specific assay of Prower-Stuart factor and Factor VII. Acta haemat. (Basel) 1961, $25,105$.

23. Hougie, C. Anticoagulant action of protamine sulphate. Proc. Soc. exp. Biol. (N. Y.) 1958, 98, 130.

24. Holemans, R., C. Vermylen, and M. Verstraete. Disappearance of Factor $\mathrm{V}$ activity after incubation of plasma with heparin and heparinoids. Thrombos. Diathes. haemorrh. (Stuttg.) 1960, 4, 303.

25. Ratnoff, O. D. Hemostatic mechanisms in liver disease. Med. Clin. N. Amer. 1963, 47, 721.

26. Barnhart, M. I., and G. F. Anderson. Cellular study of drug alteration of prothrombin synthesis. Biochem. Pharmacol. 1962, 9, 23.

27. Anderson, G. F., and M. I. Barnhart. Prothrombin synthesis in the dog. Amer. J. Physiol. 1964, 206, 929.

28. Mattii, R., J. L. Ambrus, J. E. Sokal, and I. Mink. Production of members of the blood coagulation and fibrinolysin systems by the isolated perfused liver. Proc. Soc. exp. Biol. (N. Y.) 1964, 116, 69.

29. Yarmolinsky, M. B., and G. L. de la Haba. Inhibition by puromycin of amino acid incorporation into protein. Proc. nat. Acad. Sci. (Wash.) 1959, 45, 1721.

30. Morris, A., R. Arlinghaus, S. Favelukes, and R. Schweet. Inhibition of hemoglobin synthesis by puromycin. Biochemistry 1963, 2, 1084.

31. Hemker, H. C., J. J. Veltkamp, A. Hensen, and E. A. Loeliger. Nature of prothrombin biosynthesis : preprothrombinaemia in vitamin K-deficiency. Nature (Lond.) 1963, 200, 589.

32. Seegers, W. H. Prothrombin. Cambridge, Harvard University Press, 1962.

33. John, D. W., and L. L. Miller. Submitted for publication. 